\title{
Comparison of forehead infrared thermometry with axillary digital thermometry in detecting neonatal hypothermia \& study of effects of early breast feeding and adequate clothing in maintaining neonatal temperature
}

\author{
Kurrey V. ${ }^{1}$, Sao M. ${ }^{2}$, Phuljhele S. ${ }^{3}$ \\ ${ }^{1}$ Dr.Virendra Kurrey, Associate Professor, ${ }^{2}$ Dr. Madhavi Sao, Postgraduate fellow, ${ }^{3}$ Dr. Sharja Phuljhele, Professor \& \\ Head, all authors are affiliated with the Department of Paediatrics, Pt. JNM Medical College, Raipur, C.G., India.
}

Corresponding Author: Dr. Madhavi Sao, A-84, Anandam World City, Kachna, Raipur Chhattisgarh, Email : saomadhavi@gmail.com

\begin{abstract}
Background: Neonatal hypothermia is a well-recognized important contributing factor to neonatal morbidity and mortality especially in developing countries. Axillary thermometry is the conventional method in neonates to measure body temperature. Forehead-infrared thermometry is new non-touch method that may reduce infection rate and discomfort of neonates. Objectives: To compare the accuracy of forehead infrared thermometry with axillary digital thermometry in detecting neonatal hypothermia and to determine the association of inadequate clothes and delayed initiation of breastfeeding with increased risk of hypothermia. Materials and Methods: A cross-sectional study was conducted among term neonates with age $<24$ hrs of life in the postnatal wards of tertiary care hospital. The body temperature of neonates was measured by both methods \& their accuracy was analyzed to detect hypothermia with the adequate statistical method. Association between delayed breastfeeding and inadequate clothing with neonatal hypothermia were also evaluated. Result: Mean difference (bias) of the axillary and infrared forehead readings $\left(-0.29^{\circ} \mathrm{C}\right)$ in the morning and $\left(-0.31^{\circ} \mathrm{C}\right)$ in the evening. Agreement by the Bland-Altman method in the morning $(-0.76 \& 1.33)$ and at evening (-1.33 \& 0.76) shows the transference of two techniques was inappropriate indicating that infraredthermometry cannot replace axillary digital thermometry. Subjects who were early breastfed and with adequate clothing were found to have significantly higher body temperature. Conclusion: Forehead infrared thermometry cannot replace axillary thermometry and is not recommended for neonatal temperature measurement. Early breastfeeding, covering of heads, as well as extremities, were found to be protective from hypothermia.
\end{abstract}

Keywords: Neonatal, Hypothermia, Thermometry, Axillary, Infrared

\section{Introduction}

Body temperature is an important vital sign in neonates. Prevention of neonatal hypothermia is the most essential care in newborns. Accurate body temperature measurement is crucial for detecting not only hyperthermia but also hypothermia for which neonates are more vulnerable, so accurate temperature recording remains an essential component of the neonatal care at birth and in the first few days of life [1].

Measurement of temperature in neonates can be obtained by rectal, axillary, and tympanic thermometry. Axillary temperature measurement is recommended by

Manuscript received: $14^{\text {th }}$ May 2019

Reviewed: $24^{\text {th }}$ May 2019

Author Corrected: $30^{\text {th }}$ May 2019

Accepted for Publication: $7^{\text {th }}$ June 2019 the American Academy of Pediatrics and the National Association of Neonatal Nurses. Mercury glass thermometer has been replaced by a digital thermometer that is safer and more convenient. Furthermore "minimal contact" being the guiding principle in neonatal care, more convenient techniques have been evolved to replace axillary thermometry[2].

Among the new methods, the non-contact forehead infrared thermometry is trendy in hospitals. It is simple, fast and convenient compared to the conventional methods. Due to its non-touch technique and negligible risk of cross infections, it appears to be a promising method of thermometry in neonates where minimal handling is recommended [3]. In this method, a sensor 
Original Research Article

probe measures the amount of thermal radiation (infrared) emitted from the forehead which has rich blood flow from the temporal artery[4].

Lack of knowledge amongst health workers and mothers of simple methods to maintain the warm chain from birth has been found to be the most common factor contributing to hypothermia. Suitable policies comprising simple practices such as establishing a warm delivery room, immediate drying at birth, skin to skin contact, early breastfeeding, delay in bathing the newborn, proper clothing, warm resuscitation, warm transportation, and training/ awareness, are necessary to prevent hypothermia [5].

Early and adequate breastfeeding provides enough calories to newborns to generate body heat. As up to $25 \%$ of heat loss can occur from an uncovered head so in the initial hours after birth baby head and extremities should be adequately covered[6].

In this perspective, the present study aimedto compare the forehead infrared thermometry with axillary digital thermometry in measuring neonatal temperature for detection of hypothermia.

The effects of early breast-feeding and covering the heads and extremities on neonatal temperature were also studied and assessed statistically for significance.

\section{Materials and methods}

Study setting: This study was performed in the Paediatric Department Pt. Jawaharlal Nehru Memorial Medical College \& associated Dr. B.R.AM Hospital Raipur, after approval from the institutional ethical committee.

Type of study: Prospective observational study conducted from October 2017 to March 2018.

Sampling method: A consecutive number of 400 apparently healthy term neonates with age $<24$ hrs of life were recruited for assessment of body temperature.

Inclusion criteria: Term neonates less than 24 hours of age who were kept with their mothers in postnatal wards.
Exclusion criteria: Premature labor, prolonged rupture of membranes [greater than 18 hours], gestational age < 37 weeks, perinatal asphyxia, signs of illness or major congenital anomalies.

Study methodology and data collection: After delivery, each newborn was dried and placed under a radiant warmer. Mother and newborn shared a single bed together in the postnatal ward. Intimate skin-to-skin contact between mother and newborn was not practiced except during breast feeding. Newborns body temperature was measured using an axillary digital thermometer (Omron MC-670) and infrared thermometer (Omron MC - 720).

Temperatures were recorded by both a digital thermometer and infrared forehead thermometer once in the morning (10 am to $11 \mathrm{am}$ ) and once in the evening (7 pm to $8 \mathrm{pm}$ ) after a shift to the postnatal ward.

The digital thermometer was put with the sensor in the newborn armpits after activating the button power and waiting until the alarm sounds for its temperature display. An Infrared forehead thermometer was placed 1 to $3 \mathrm{~cm}$ from mid-forehead and the start button was pressed for recording. The measurement was completed in 1 second with a long beep.

The data was collected using an especially designed proforma having details of postnatal age of the newborns in hours, gestational age, birth weight, recorded temperatures of the newborn, received early breastfeeding or not, head/extremities covered or not and temperature of the postnatal ward.

\section{Statistical analysis}

- Data were expressed in percentage and Mean.

- To study the statistical agreement between two methods, the Lin Concordance correlation coefficient and a newer method of comparison Bland and Altman plot method were applied.

- The Student's t-test was used to check the significance of mean difference parametric data.

- A mean difference of temperature $\pm 0.5^{\circ} \mathrm{C}$ was considered clinically acceptable.

\section{Results}

The body temperature of 400 neonates was measured including 207 (51.75\%) males and $193(48.25 \%)$ females. The mean birth weight was $2840 \pm 359$ grams. 359 (89.8\%) subjects had birth weight 2.5-4.2 Kg while, 41 (10.2\%) subjects had birth weight 1.5-2.499 kg. The temperature of all the neonates was measured by both the techniques in the morning as well as evening. 
Original Research Article

Table-1: Comparison of IR forehead and digital axillary temperature in neonates.

\begin{tabular}{|c|c|c|c|c|}
\hline \multirow{2}{*}{ Temperature } & \multicolumn{2}{|c|}{$\begin{array}{c}\text { Morning and Evening IR forehead } \\
\text { temperature in neonates }\end{array}$} & \multicolumn{2}{c|}{$\begin{array}{c}\text { Morning and Evening digital } \\
\text { axillary temperature in neonates }\end{array}$} \\
\cline { 2 - 5 } & Morning & Evening & Morning & $14.20 \%$ \\
\hline $\begin{array}{c}\text { Moderate hypothermia } \\
32.0-35.9^{\circ} \mathrm{C}\end{array}$ & $7.50 \%$ & $3.80 \%$ & $31.50 \%$ & $40 \%$ \\
\hline $\begin{array}{c}\text { Mild hypothermia } \\
36.0-36.4^{\circ} \mathrm{C}\end{array}$ & $4.20 \%$ & $4 \%$ & $54.20 \%$ & $45.80 \%$ \\
\hline $\begin{array}{c}\text { Normal } \\
36.5-37.5^{\circ} \mathrm{C}\end{array}$ & $88.20 \%$ & $92.20 \%$ & $\mathbf{1 0 0}$ & $\mathbf{1 0 0}$ \\
\hline Total & $\mathbf{1 0 0}$ & $\mathbf{1 0 0}$ & \\
\hline
\end{tabular}

Morning and evening IR forehead temperature in the study subjects was assessed; Table 1 shows that in the morning $11.70 \%$ neonates and in the evening $7.80 \%$ were in hypothermia. Hypothermia was detected by digital axillary thermometer in $45.70 \%$ of newborns in the morning and $44.20 \%$ newborns in the evening. The difference in percentages of morning and evening hypothermia cases shows that by IR forehead temperature measurement $34 \%$ and $36.40 \%$ neonates were less detected for hypothermia in comparison to a digital axillary method.

Table-2: Mean, range, mean difference and limits of agreement of the temperature measurements.

\begin{tabular}{|c|c|c|c|c|c|c|c|c|}
\hline \multirow{2}{*}{ Variable } & \multicolumn{2}{|c|}{$\begin{array}{c}\text { The Axillary } \\
\text { temperature in }{ }^{\circ} \mathbf{C}\end{array}$} & \multicolumn{2}{|c|}{$\begin{array}{c}\text { The infrared } \\
\text { temperature in }{ }^{\circ} \mathbf{C}\end{array}$} & $\begin{array}{c}\text { Mean } \\
\text { difference } \\
\text { in }{ }^{\circ} \mathbf{C}\end{array}$ & $\begin{array}{c}\text { The lower } \\
\text { limit of } \\
\text { agreement }\end{array}$ & $\begin{array}{c}\text { The upper } \\
\text { limit of } \\
\text { agreement }\end{array}$ & p-value \\
\hline Morning & 36.48 & $35.5-38.7$ & 36.77 & $34.6-38$ & -0.29 & -0.7627 & 1.3388 & $<0.0001$ \\
\hline Evening & 36.52 & $34.8-37.8$ & 36.83 & $35.8-38.3$ & -0.31 & -1.3388 & 0.7627 & $<0.0001$ \\
\hline
\end{tabular}

The mean, range, mean difference and 95\% limits of agreement of the temperature measurements are shown in Table 2. Considering all the 400 pair of readings, the mean axillary temperature at morning was $36.48^{\circ} \mathrm{C}$ and the mean infrared temperature at morning was $36.77^{\circ} \mathrm{C}$. The mean axillary temperature in the evening was $36.83^{\circ} \mathrm{C}$ and the mean infrared temperature in the evening was $36.83^{\circ} \mathrm{C}$. Therefore, the mean infrared temperature recorded was significantly higher than the mean axillary temperature ( $\mathrm{p}$-value $<0.0001)$.

The mean difference (bias) of the axillary and infrared forehead readings in the morning was $-0.29^{\circ} \mathrm{C}$ and at evening was $-0.31^{\circ} \mathrm{C}$. This is less than the clinically acceptable value set at $\pm 0.5^{\circ} \mathrm{C}$. Infrared readings tend to be a little greater than the axillary readings. The lower and upper limits of the agreement by the Bland-Altman method in the morning were $0.7627 \& 1.3388$, and at evening $-1.3388 \& 0.7627$ respectively (Figure $1 \& 2$ ). This range of the limits of around $2^{\circ} \mathrm{C}$ is too wide to be clinically acceptable.

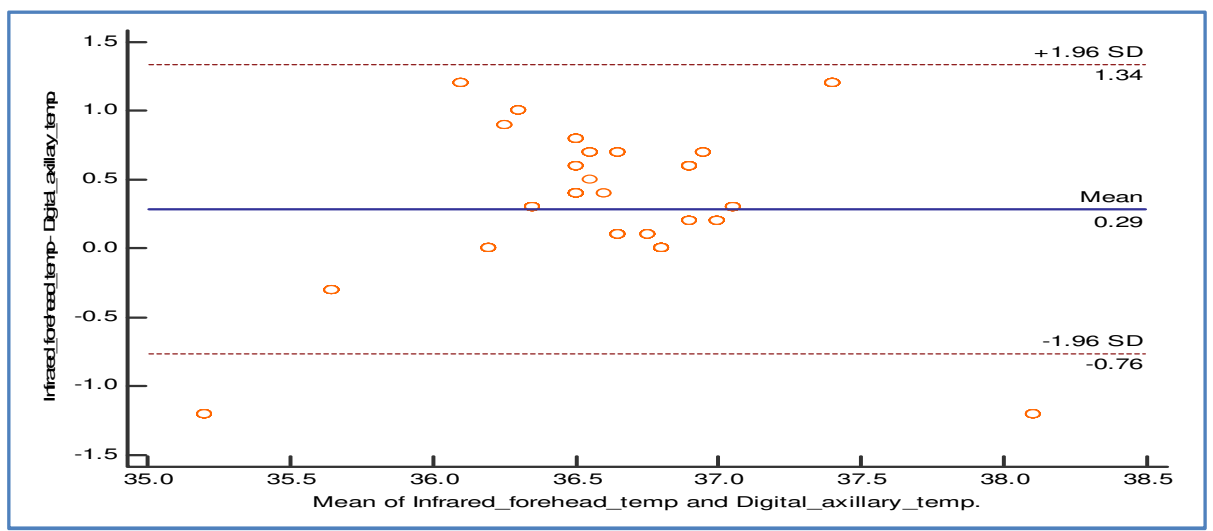

Figure-1: Bland Altman plot for comparability of IR forehead temperature and digital axillary temperature in the morning 
Original Research Article

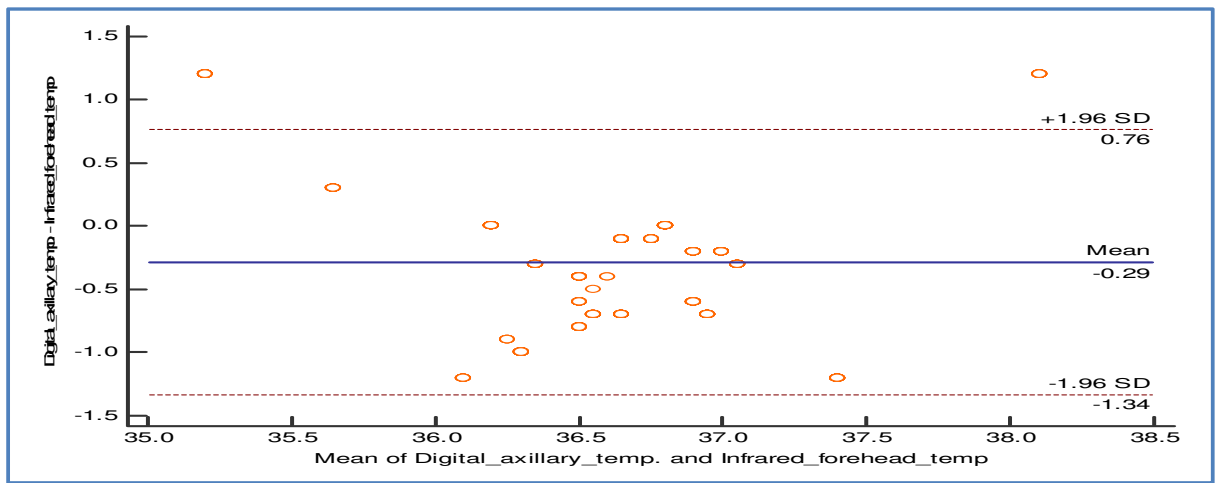

Figure 2: Bland Altman plot for comparability of IR forehead temperature and digital axillary temperature in the evening

Correlation analysis between morning and evening IR forehead temperature and the digital axillary temperature was performed using Pearson correlation analysis. Table 3 shows that only mild correlation exists between two tests making transference of the technique of measurement of temperature inappropriate.

Table-3: Correlation between IR forehead temperature and digital axillary temperature

\begin{tabular}{|c|c|c|c|c|}
\hline \multicolumn{2}{|c|}{ Variable } & $\begin{array}{c}\text { Correlation } \\
\text { coefficient r }\end{array}$ & P value & Interpretation \\
\hline $\begin{array}{c}\text { Morning IR forehead } \\
\text { temperature }\end{array}$ & $\begin{array}{c}\text { Morning digital } \\
\text { axillary temperature }\end{array}$ & 0.567 & $<0.0001$ & Mild upstream correlation \\
\hline $\begin{array}{c}\text { Evening IR forehead } \\
\text { temperature }\end{array}$ & $\begin{array}{c}\text { Evening digital } \\
\text { axillary temperature }\end{array}$ & 0.374 & $<0.0001$ & Mild upstream correlation \\
\hline
\end{tabular}

Lin's Concordance correlation coefficient between IR forehead temperature and digital axillary temperature in morning and evening was calculated. The sample concordance correlation coefficient $(\rho c)$ for the morning was $0.4834(0.42-0.53)$ and for the evening $(\rho c)$ was $0.4933(0.44-0.54)$ indicating a moderate degree of concordance, thus rendering transference of technique is inappropriate.

Table-4: Effect of head covering on morning and evening temperature

\begin{tabular}{|l|c|c|c|c|c|c|c|}
\hline & $\begin{array}{c}\text { Head covered } \\
\text { morning }\end{array}$ & $\mathbf{N}$ & Mean & S.D. & $\begin{array}{c}\text { S.E. of } \\
\text { mean }\end{array}$ & T & p-value \\
\hline \multirow{2}{*}{$\begin{array}{l}\text { Morning digital axillary temp } \\
\text { of the newborn }\left({ }^{\circ} \mathrm{C}\right)\end{array}$} & Yes & 210 & 36.6724 & 0.50727 & 0.035 & 8.26 & $<0.0001$ \\
\cline { 2 - 8 } & No & 190 & 36.28 & 0.43476 & 0.03154 & & \\
\hline \multirow{2}{*}{$\begin{array}{l}\text { Evening digital axillary temp } \\
\text { of the newborn }\left({ }^{\circ} \mathrm{C}\right)\end{array}$} & Yes & 219 & 36.6329 & 0.51126 & 0.03455 & 4.63 & $<0.0001$ \\
\cline { 2 - 8 } & No & 181 & 36.3978 & 0.4971 & 0.03695 & & \\
\hline
\end{tabular}

Table 4 shows the effect of head covering on the morning (mean difference $0.39^{\circ} \mathrm{C}$ ) and evening temperature (mean difference $0.24^{\circ} \mathrm{C}$ ) was performed using Student's unpaired t-test. A significant difference $(\mathrm{p}<0.001)$ was observed between two temperatures indicating that temperature was significantly higher when the head was covered.

Table-5: Effect of extremities covering on morning and evening temperature

\begin{tabular}{|l|c|c|c|c|c|c|c|}
\hline & $\begin{array}{c}\text { Extremities } \\
\text { covered } \\
\text { morning }\end{array}$ & N & Mean & S.D. & $\begin{array}{c}\text { S.E. of } \\
\text { mean }\end{array}$ & t p-value \\
\hline $\begin{array}{l}\text { Morning digital axillary } \\
\text { temp of the newborn }\left({ }^{\circ} \mathrm{C}\right)\end{array}$ & Yes & 200 & 36.709 & 0.51346 & 0.03631 & 9.65 & $<0.0001$ \\
\cline { 2 - 8 } & No & 200 & 36.263 & 0.40416 & 0.02858 & & \\
\hline $\begin{array}{l}\text { Evening digital axillary } \\
\text { temp of the newborn }\left({ }^{\circ} \mathrm{C}\right)\end{array}$ & Yes & 285 & 36.6558 & 0.52341 & 0.031 & 8.54 & $<0.0001$ \\
\cline { 2 - 8 } & & 115 & 36.2061 & 0.332 & 0.03096 & & \\
\hline
\end{tabular}


Table 5 shows the effect of extremities covering on the morning (mean difference $0.45^{\circ} \mathrm{C}$ ) and evening temperature (Mean difference $0.45^{\circ} \mathrm{C}$ ) was performed using Student's unpaired t-test. A significant difference was observed between two temperatures indicating that temperature was significantly higher when the head was covered.

Table-6: Effect of early breastfeeding on temperature.

\begin{tabular}{|l|c|c|c|c|c|c|c|}
\hline \multicolumn{1}{|c|}{ Variable } & $\begin{array}{c}\text { Early } \\
\text { Breastfeeding } \\
\text { within 1 hr }\end{array}$ & N & Mean & S.D. & S.E.M. & t & P-value \\
\hline $\begin{array}{l}\text { Morning digital axillary temp } \\
\text { of the newborn }\left({ }^{\circ} \mathbf{C}\right)\end{array}$ & Yes & 186 & 36.5183 & 0.59091 & 0.04333 & 1.175 & 0.241 \\
\cline { 2 - 9 } & No & 214 & 36.4579 & 0.43282 & 0.02959 & & \\
\hline $\begin{array}{l}\text { Evening digital axillary temp } \\
\text { of the newborn }\left({ }^{\circ} \mathbf{C}\right)\end{array}$ & Yes & 186 & 36.6667 & 0.54621 & 0.04005 & 5.211 & $<0.0001$ \\
\cline { 2 - 9 } & No & 214 & 36.4047 & 0.45921 & 0.03139 & & \\
\hline
\end{tabular}

In Table 7 effect of early breastfeeding on temperature was assessed using Student's unpaired t-test. While early breastfeeding did not impact morning temperature, subjects who were early breastfed were found to have significantly higher body temperature in the evening.

\section{Discussion}

Infrared thermometry is a new method compared to conventional methods of temperature measurement which is rapid and easy to use. As it is a non-touch technique there is a negligible chance of cross infections in neonates and very suitable to use. Various studies have been conducted to compare its accuracy with the axillary method of temperature measurement.

In the present study, a high value of bias and wide limits of agreement were noted. The mean difference (bias) of the axillary and infrared forehead readings in the morning was $-0.29^{\circ} \mathrm{C}$ and at evening was $-0.31^{\circ} \mathrm{C}$. This is less than the clinically acceptable value set at $\pm 0.5^{\circ} \mathrm{C}$. Infrared readings tend to be a little greater than the axillary readings. The lower and upper limits of the agreement by the Bland-Altman method in the morning were $-0.7627 \& 1.3388$, and at evening $-1.3388 \&$ 0.7627 respectively (Table 2). This range of the limits of around $2^{\circ} \mathrm{C}$ is too wide to be clinically acceptable.

Among the studies comparing axillary and forehead infrared thermometry, Sethi et al. 2013noted a mean difference of $-0.5 \mathrm{C}$ and limits of agreement as $-2.3,1.2$ in their study comparing axillary and forehead infrared thermometry[7]. Megha S Patel et al. 2014 found a very high mean difference of $-1.5 \mathrm{C}$ and $95 \%$ limits of agreement as $-2.7,-0.3$ with infrared values higher than the axillary values in all the pairs of readings[8]. Ilaria Merusiet al 2015 recorded a mean difference of $0.35 \mathrm{C}$ with $95 \%$ limits of agreement as $-0.45,1.17[9]$ and Uslu et al. 2011 noted a bias of $-0.55 \mathrm{C}[10]$. In contrast, Chiappini et al. 2011 reported a good agreement (mean difference $=0.070 \mathrm{C}, 95 \%$ limits of agreement: $[-0.62$, 0.76]) between Infrared forehead thermometry (IRFT) and axillary thermometry using glass mercury thermometer in paediatric population[11]. Kotsia et al. 2015reported that poor correlation existed between forehead temperature and digital axillary temperature [12]. They all concluded that infrared non-contact thermometers cannot be recommended for the measurement of body temperature in neonates in an intensive care setting where accurate temperature measurement is required.

In the present study, the effect of head covering on the morning (mean difference $0.39^{\circ} \mathrm{C}$ ) and evening temperature (mean difference $0.24^{\circ} \mathrm{C}$ ) was assessed and the significant difference was observed $(\mathrm{p}<0.001$ between two temperatures indicating that temperature was significantly higher when the head was covered. Also, the effect of extremities covering on the morning (mean difference $0.45^{\circ} \mathrm{C}$ ) and evening temperature (mean difference $0.45^{\circ} \mathrm{C}$ ) shows a significant difference was $(p<0.001)$ between two temperatures indicating that temperature was significantly higher when the head was covered. McCall et al. 2006 stressed the importance of covering the head and extremities of babies in order to prevent hypothermia[13].

Delavar et al. 2014 noted that hypothermia was not found to be associated with keeping mother and baby together, skin-to-skin contact, gestational age, delayed appropriate clothing, breastfeeding[14]. In the present study who were early breastfed were found to have significantly higher body temperature $(\mathrm{OR}=2.78)$. Studies suggesting similar findings have observed that breastfeeding is found to be protective against hypothermia and delayed breastfeeding $>24$ hours after birth is associated with increased risk of neonatal hypothermia (OR 3.32) $[15,16]$. 


\section{Conclusion}

Infrared forehead thermometer readings do not comparably correspond to axillary digital thermometer \& infrared forehead thermometer may miss the diagnosis of hypothermia in the neonate.

It was also observed that the covering of head and extremities and early breastfeeding are protective against hypothermia. Hereby it is recommended infrared forehead thermo-meter may not be useful for temperature monitoring in neonates.

Funding: Nil, Conflict of interest: None initiated, Permission from IRB: Yes

\section{References}

1. World Health Organization. Thermal control of the newborn: a practical guide. Geneva: World Health Organization; 1993.

2. Martin SA, Kline AM. Can there be a standard for temperature measurement in the pediatric intensive care unit? AACN Clin Issues. 2004 Apr-Jun;15(2):254-66.

3. Fortuna EL, Carney MM, Macy M, Stanley RM, Younger JG, Bradin SA. Accuracy of non-contact infrared thermometry versus rectal thermometry in young children evaluated in the emergency department for fever. Journal of Emergency Nursing. 2010 Mar 1; 36 (2):101-4.

4. Bland JM, Altman DG. Statistical methods for assessing agreement between two methods of clinical measurement. Lancet. 1986 Feb 8;1(8476):307-10.

5. Çınar ND, Filiz TM. Neonatal thermoregulation. Journal of Neonatal Nursing. 2006 Apr 1;12(2):69-74.

6. Forster DA, McLachlan HL. Breastfeeding initiation and birth setting practices: a review of the literature. $\mathrm{J}$ Midwifery Womens Health. 2007 May-Jun; 52 (3): 273-80.

7. Sethi A, Patel D, Nimbalkar A, et al. Comparison of forehead infrared thermometry with axillary digital thermometry in neonates. Indian Pediatr. 2013 Dec;50 (12):1153-4. Epub 2013 Jul 5.
8. Patel MS, Kakkad KM, Patel SV, et al. Acomparative study of accuracy of non-contact infrared thermometry and axillary digital thermometry in neonates. Gujarat Med. J. 2014;69(2):103-4.

9. Placidi G, Merusi I, Gagliardi L. Rectal, axillary or skin temperature in newborns. J Preg Child Health. 2014; 1 (123):2.

10. Uslu S, Ozdemir H, Bulbul A, et al. A comparison of different methods of temperature measurements in sick newborns. Journal of Tropical Pediatrics. 2011 Jan 17;57(6):418-23.

11. Chiappini E, Sollai S, Longhi R, et al. Performance of non-contact infrared thermometer for detecting febrile children in hospital and ambulatory settings. J Clin Nurs. 2011 May;20(9-10):1311-8. doi: 10.1111/j. 1365-2702.2010.03565.x.

12. Efijenia Kotsia, A. Attilakos, E. Tsekoura, et al. Temperature Assessment and Accuracy of Different Thermometer Devices in Neonates. International Journal of Nursing and Health Science Vol. 2, No. 6, 2015, pp. 64-69.

13. Mccall, Emma \&Alderdice, Fiona \& Halliday, Henry \& Jenkins, John \& Vohra, S. (2006). Interventions to prevent hypothermia at birth in preterm and/ or low birth weight babies. Evidence-Based Child Health: A Cochrane Review Journal. 1. 287 - 324. 10.1002/eb

14. Delavar MA, Akbarianrad Z, Mansouri MM, Yahyapour M. Neonatal hypothermia and associated risk factors at baby friendly hospital in Babol, Iran. Annals of medical and health sciences research. 2014; 4(8):99-103.

15. Mullany LC, Katz J, Khatry SK, LeClerq SC, et al. Neonatal hypothermia and associated risk factors among newborns of southern Nepal. BMC Med. 2010 Jul 8;8:43. doi: 10.1186/1741-7015-8-43.

16. Raj JP, Sathish Kumar T.Prevalence of hypothermia among normal term neonates in a south Indian city and assessment of practice and knowledge risk factors among mothers-a hospital based cross-sectional study. 2015.

\section{How to cite this article?}

Kurrey V, Sao M, Phuljhele S. Comparison of forehead infrared thermometry with axillary digital thermometry in detecting neonatal hypothermia \& study of effects of early breast feeding and adequate clothing in maintaining neonatal temperature. Int J Pediatr Res. 2019; 6(06):286-291.doi:10.17511/ijpr.2019.i06.04 